\title{
Impact of Equatorial Wind Stress on Ekman Transport During the Mature Phase of the Indian Ocean Dipole
}

\section{Linfang Zhang ( $D$ 1147984953@qq.com )}

College of Global Change and Earth System Sciences(GCESS),Beijing Normal

University,Beijing,100875,China https://orcid.org/0000-0001-9762-2153

\section{Yaokun Li}

College of Global Change and Earth System Sciences(GCESS),Beijing Normal University ,Beijing,100875,China

\section{Jianping Li}

Laboratory for Ocean Dynamics and Climate,Pilot Qingdao National Laboratory for Marine Sciences and Technology,Qingdao,266237,China

\section{Research Article}

Keywords: Indian Ocean dipole (IOD), meridional motion, Ekman transport, sea surface temperature anomaly (SSTA)

Posted Date: September 13th, 2021

DOl: https://doi.org/10.21203/rs.3.rs-390257/v1

License: (c) (1) This work is licensed under a Creative Commons Attribution 4.0 International License. Read Full License

Version of Record: A version of this preprint was published at Climate Dynamics on February 21st, 2022. See the published version at https://doi.org/10.1007/s00382-022-06183-7. 
1 Impact of Equatorial Wind Stress on Ekman Transport During the Mature

\section{Phase of the Indian Ocean Dipole}

Linfang Zhang ${ }^{1}$, Yaokun $\mathrm{Li}^{1 *}$, Jianping $\mathrm{Li}^{2,3}$

1. College of Global Change and Earth System Sciences (GCESS), Beijing Normal University, Beijing, 100875, China

2. Frontiers Science Center for Deep Ocean Multispheres and Earth System (FDOMES)/Key Laboratory of Physical Oceanography/Institute for Advanced Ocean Studies, Ocean University of China, Qingdao 266100, China.

3. Laboratory for Ocean Dynamics and Climate, Pilot Qingdao National Laboratory for Marine Science and Technology, Qingdao 266237, China.

* Corresponding author address:

\section{Submitted to Climate Dynamics}

$$
\text { Dr. Yaokun Li }
$$

Associate Professor, College of Global Change and Earth System Sciences, Beijing Normal University, Beijing 100875, China

E-mail: liyaokun@bnu.edu.cn 
This paper investigates the impact of equatorial wind stress on the equatorial Ekman transport during the Indian Ocean dipole (IOD) mature phase. The results show that the equatorial zonal wind stress directly drives the meridional motion of seawater at the upper levels. In normal years, the zonal wind stress south of the equator is easterly and that north of the equator is westerly, which contributes to southward Ekman transport at the upper levels to form the climatological Indian Ocean shallow meridional overturning circulation. During the years of positive IOD events, abnormal easterly winds near the equator bring southward Ekman transport south of the equator while forms a pair of small circulation cells that are symmetric about the equator at the upper levels (approximately $100 \mathrm{~m}$ deep). The abnormal circulation cell south (north) of the wind stress and Ekman transport anomaly but the influence is weak. 


\section{Introduction}

Ekman transport plays an important role in the meridional overturning circulation and its associated heat transport in the Indian Ocean. For instance, Lee and Marotzke (1998) demonstrated that the time-varying Ekman flow of the shallow MOC and its barotropic compensation can explain most of the seasonal variation of heat transfer in the IO. Fischer et al. (2002) pointed out that Ekman flow related to mesoscalemodulated transport is important to the overall upper ocean heat budget in the Arabian Sea. Hu et al. (2005) calculated the difference between the meridional streamfunction of the North Indian Ocean (north of $7^{\circ} \mathrm{S}$ ) every year and all the annual mean meridional streamfunction, and obtained the meridional streamfunction anomaly every year. Then, the positive and negative typical years were selected for composite analysis. It was found that the annual mean meridional heat transfer anomalies of the two typical years showed opposite changes at each latitude.

Many studies have shown that the onset and retreat of the Indian Monsoon mainly promote seasonal cycles of the Ekman transport (Garternicht and Schott 1997; Lee and Marotzke 1997; Li and Chao 2013). In particular, Lee and Marotzke (1998) concluded that the maximum seasonal variations of the streamfunction at $10^{\circ} \mathrm{N}$ and $10^{\circ} \mathrm{S}$ are related to monsoon reversal. During the summer monsoon season, westerlies (easterlies) prevail north (south) of the equator which drive southward Ekman transport in the entire IO region. During the winter monsoon season, the westerlies change direction to easterlies which leads to northward Ekman transport in areas north of the equator (Schott et al. 2002). Additional studies have suggested that the interannual and decadal changes of the Ekman transport are also linked to corresponding variations in the wind field. For example, Lee (2004) found that the southeast trade winds over the southern IO north of approximately $20^{\circ} \mathrm{S}$ experienced a near-decadal (1992-2000) weakening so 
the strength of the Ekman transport controlled by these winds diminished during this period. In contrast, the southwesterlies over the northern IO showed little decadal change during this period and hence, the Ekman transport related to the cross-equatorial cell remained relatively steady.

In terms of wind variations in the IO, some studies have found that during an Indian Ocean dipole (IOD) event, the surface wind field over the tropical IO varies greatly, especially its zonal component (Li et al. 2003; Webster et al. 1999; Zhang et al. 2018). This fact indicates that wind anomalies accompanying the IOD may play a vital role in controlling the corresponding equatorial Ekman transport. However, few studies have been conducted to address the relationship between wind anomalies over the equator and the Ekman transport. Wang et al. (2014) decomposed the deep MOC (DMOC) in the IO into Ekman and geostrophic transport, external mode and a residual term. They found that each dynamic component plays a different role in different stages of the IOD and that the changes of relative contributions of each component are related to SST and wind anomalies, which are related to the IOD. Their main focus was the deep thermohaline circulation and the Ekman layer was not discussed. Sherin et al. (2018) pointed out that wind anomalies during IOD events may affect variations in the East India Coastal Current (EICC) and that abnormal northward (southward) transport may occur in the winter during positive (negative) IOD events, usually up to $5 \mathrm{~Sv}$ (7 Sv). They emphasized the influence of the IOD on coastal currents and did not focus on the equatorial Ekman transport. Therefore, the impact of the wind field during IOD peak periods on the equatorial Ekman transport is still unclear and needs further investigation.

This paper aims to deal with this unsolved question and proposes a physical mechanism by which surface winds affect the equatorial Ekman transport during the 
IOD mature period. The remainder of this paper is organized as follows: section 2 describes the data and methodology used in the study; section 3 presents the statistical relationships between equatorial wind stress and the Ekman transport during the IOD mature phase and section 4 investigates the possible physical mechanisms; section 5 discusses the influence of ENSO; and section 6 summarizes the findings.

\section{Data and methodology}

The Simple Ocean Data Assimilation (SODA) version 2.1.6 product is used to calculate the shallow streamfunction in the IO. SODA version 2.1.6 has a horizontal resolution of $0.5^{\circ} * 0.5^{\circ}$ and vertical resolution of 40 levels which extend from near the surface to a depth of 5,000 meters with a nonuniform distribution. These data cover the time span from January 1958 to December 2008. The physical variables include temperature, salinity, velocity, and wind stress. SODA assimilates a large amount of observational data (Carton et al. 2000) and is an important data source for ocean research (Schott et al. 2002; Xie et al. 2002).

The stream function of MOC in the IO is calculated by

$$
\psi(\varphi, z)=a \int_{\lambda_{w}}^{\lambda_{e}} \int_{z_{s}}^{z} v(\lambda, \varphi, z) \cos \varphi d z d \lambda,
$$

where $\lambda, \varphi, z$ are the longitude, latitude, and depth, respectively; $\lambda_{w}, \lambda_{e}$ are the western and eastern coasts of the IO, respectively; $z_{S}$ is the topography; and $a$ is the Earth's radius. Since we mainly discuss the wind-driven Ekman transport, we only analyzed the stream function in the upper 500 meters. It is found that the circulation anomaly caused by equatorial wind stress mainly occurs in the Ekman layer near the equator during the IOD mature period. So EETAI (equatorial Ekman transport anomaly intensity) is represented by the maximum value of circulation anomaly caused by equatorial wind stress during the mature period of IOD. 


$$
\begin{gathered}
U_{E} \equiv \int_{-D_{E}}^{0} u d z=\frac{1}{\rho_{o} f_{115}^{113}} \\
V_{E} \equiv \int_{-D_{E}}^{0} v d z=-\frac{111 q^{x}}{\rho_{o} f}
\end{gathered}
$$

118 Where $U_{E}$ is the zonal Ekman transport, $V_{E}$ is the meridional Ekman transport, and $D_{E}$ represents the thickness of Ekman layer, which is about tens of meters to more than 100 meters in the tropical ocean (Stewart, 2004). $u$ is the zonal velocity of sea water,

$121 v$ is the meridional velocity of sea water, $\rho_{0}$ represents the density of sea water and the average value is $1025 \mathrm{~kg} \cdot \mathrm{m}^{-3}, f$ is the Coriolis coefficient, and $\tau^{y}$ and $\tau^{x}$ are the meridional wind stress and zonal wind stress. Ekman layer transport is the transport of the sea surface boundary layer directly driven by the wind stress. Its direction is perpendicular to the wind stress (it points to the right of the wind stress in the northern hemisphere and to the left of the wind stress in the southern hemisphere). Its magnitude is related to the wind stress intensity and latitude.

The spatial variation of wind stress (and the variation of Coriolis parameters with latitude) can cause the spatial variation of Ekman layer transport, which leads to convergence, divergence and corresponding upward and downward motion, which is called Ekman pumping. The Ekman pumping in the IO is calculated by

$$
\left.w\right|_{z=-D_{E}}=\frac{\partial}{\partial x}\left(\frac{\tau^{y}}{\rho_{o} f}\right)-\frac{\partial}{\partial y}\left(\frac{\tau^{x}}{\rho_{o} f}\right)
$$

Where $\rho_{0}$ is the density of sea water, with an average value of $1025 \mathrm{~kg} \cdot \mathrm{m}^{-3}, f$ is the Coriolis coefficient, and $\tau^{y}$ and $\tau^{x}$ are the meridional and latitudinal wind stress. The Sverdrup transport in the IO is calculated by

$$
V_{y}=\frac{1}{\beta \rho_{0}}\left(\frac{\partial \tau^{y}}{\partial x}-\frac{\partial \tau^{x}}{\partial y}\right)
$$


the motionless depth (the vertical range exceeds the depth of Ekman layer, which is called "wind-driven circulation layer"), which is called Sverdrup transport. $\rho_{0}$ is the density of sea water, with an average value of $1025 \mathrm{~kg} \cdot \mathrm{m}^{-3}, \beta$ is the change rate of Coriolis coefficient with latitude, and $\tau^{y}$ and $\tau^{x}$ are the meridional and latitudinal wind stress.

We applied the Hadley center SST dataset (Rayner et al. 2003) to calculate the Dipole Mode Index (DMI), which was defined as the difference in SST anomalies between the west pole $\left(50^{\circ}-70^{\circ} \mathrm{E}, 10^{\circ} \mathrm{S}-10^{\circ} \mathrm{N}\right)$ and east pole $\left(90^{\circ}-110^{\circ} \mathrm{E}, 10^{\circ} \mathrm{S}-0^{\circ}\right)$ by Saji et al. (1999). Based on the threshold of 1.0 from the standardized SON DMI time series, we select the positive phase years ( $>1)$ of IOD, and based on the threshold of -1 , we choose the negative phase years $(<-1)$ of IOD, respectively. The Niño-3.4 index, which is calculated from the area-averaged SSTAs over the equatorial central Pacific $\left(5^{\circ} \mathrm{S}-5^{\circ} \mathrm{N}, 120^{\circ}-170^{\circ} \mathrm{W}\right)$ by the Climate Prediction Center (CPC) using National Oceanic and Atmospheric Administration (NOAA) ERSST V5 data (Huang et al. 2017), is used to describe ENSO. The statistical diagnosis methods used include correlation coefficients and composite differences. The statistical significance of the results was determined by the Student's t test.

The partial regression coeffcient is written as (Jiang and Li 2019):

$$
C_{Y(B \mid A)}=\frac{R_{Y B}-R_{Y A^{*} R_{A B}}}{\sqrt{1-R_{A B}^{2}}} * \frac{S_{Y}}{S_{B \mid A}}
$$

Where is $Y$ represents the regression variable streamfunction, $B$ represents the zonal wind stress in the box in figure 2 , and $A$ is Niño-3.4 index that is proposed to remove. The term $C_{Y(B \mid A)}$ is the partial regression coefficient between streamfunction $Y$ and 
zonal wind stress $B$ after the infuence of Niño-3.4 index $A$ is removed from $B . R_{Y B}$ denotes the correlation coefficient of streamfunction $Y$ and zonal wind stress $B ; R_{Y A}$ is the correlation coefcient of streamfunction $Y$ and Niño-3.4 index $A ; R_{A B}$ is the correlation coefficient of Niño-3.4 index $A$ and zonal wind stress $B . S_{Y}, S_{B \mid A}$ in the equation denotes the standard deviation of streamfunction $Y$ and the standard deviation of zonal wind stress $B$ after removing Niño-3.4 index $A$.

\section{Relationship between wind stress and equatorial Ekman transport}

The IOD is closely related to the equatorial zonal wind in the IO. According to Saji et al. (1999) and Wang et al. (2014), the cold SSTAs, which accompany the nearby southeasterly wind anomaly, first appear in the southeast tropical IO from May to June (Fig. 1a). In the following months, the cold SSTAs intensify and expand along the Indonesian coastline to the equator while the western tropical IO begins to warm which is consistent with the increasing zonal winds along the equator and in Sumatra's coastal region (Fig. 1b). A sharp peak of these characteristics occurs in October and then quickly subsides (Fig. 1c, d). Since this relationship reaches its peak in autumn, we show the correlation coefficient distributions of the September-October-November (SON) DMI with SST and wind stress in the IO (Fig. 2). The spatial structure of the correlation between SON DMI and SST features a typical IOD pattern with significant negative correlation coefficients off the coast of Indonesia and significant positive correlation coefficients in the central and western Indian Ocean (shaded in Fig. 2). Meanwhile, the significant easterly anomalies which prevail in the central and eastern tropical IO suggest a tightly coupled relationship between the IOD and zonal wind 
stress (vectors in Fig. 2). To further characterize this relationship, a zonal wind stress index (ZWI) is defined by calculating the average zonal wind stress within a box (e.g., $\left.10^{\circ} \mathrm{S}-10^{\circ} \mathrm{N}, 70^{\circ} \mathrm{E}-97^{\circ} \mathrm{E}\right)$ where the most significant easterly anomalies prevail. It is obvious that the time series of DMI and ZWI (see in Fig. 3b) are highly correlated (the correlation coefficients reach as high as -0.81 and exceeding the $99 \%$ significance level).

Considering the driving effect of the zonal wind stress on the equatorial Ekman transport, Fig. 3a shows the seasonal correlations between the ZWI and the EETAI. Based on these results, the ZWI is most significantly correlated with the EETAI during the autumn season (correlation coefficient is 0.82 ), while the zonal wind stress shows certain relationships on the EETA in other seasons.

Fig. 4 further shows spatial correlation map between the ZWI and shallow streamfunction in the autumn. The correlations show a certain symmetry about the equator but with generally opposite distributions in the upper and deep levels. At depths of approximately 100 meters, the region between $10^{\circ} \mathrm{S}-0^{\circ}$ exhibits significant positive correlations while the northern IO region between $0^{\circ}-25^{\circ} \mathrm{N}$ shows significant negative correlations. At depths greater 100 meters, the positive and negative correlations switch their locations.

The above analysis suggests that there is a close statistical relationship between the zonal wind stress during the IOD mature period and equatorial Ekman transport for both time series and spatial patterns. In the following section, we further explore the physical mechanisms that equatorial zonal wind stress variations associated with the IOD mature phase could drive the corresponding equatorial Ekman transport variations. 


\section{Impact of equatorial zonal wind stress on the equatorial Ekman transport}

\section{a. Volume transport induced by wind stress}

The equatorial wind stress in the mature phase of IOD can drive Ekman transport which has a direct impact on the shallow MOC. Fig. 5a presents a correlation map of the ZWI with Ekman transport (vectors) and Ekman pumping (shading) calculated from the wind stress in the SON. We do not portray Ekman transport near the equator $\left(5^{\circ} \mathrm{S}\right.$ $5^{\circ} \mathrm{N}$ ) since it is undefined at the equator. As shown in the figure, the westerly wind stress anomalies are statistically associated with southward Ekman transport at the northern IO while they are statistically associated northward Ekman transport from $10^{\circ} \mathrm{S}$ to the equator. This indicates downward Ekman pumping due to seawater convergence near the equator. However, away from the equator, accelerating southward Ekman transport north of the equator leads to seawater divergence and hence upward Ekman pumping. The same upward Ekman pumping south of the equator extends to approximately $15^{\circ} \mathrm{S}$. It is clear that downward seawater motion near the equator and upward motions adjacent to downward motions will form two meridional cells which are symmetric about the equator in the Ekman layer. This implies that when easterly anomalies prevail near the equator, they can drive two anomalous meridional cells in the tropical IO. Since Ekman transport is not defined at the equator, we use Ekman transport difference between $5^{\circ} \mathrm{S}$ and $5^{\circ} \mathrm{N}$ to represent cross-equatorial Ekman transport (CEET). A comparison of SON ZWI (SON DMI) and the CEET shows that the correlation coefficient reaches $0.98(-0.77)$, which is beyond the $99 \%$ confidence level (Fig.5b). This indicates that when the DMI grows, the easterly is enhanced and the southward Ekman transport increases (value decreases) in autumn, and on the contrary, it weakens.

To further demonstrate the physical linkage between equatorial wind stress and 
Ekman transport in the tropical IO, Fig. 6 presents composites of Ekman transport and Ekman pumping that equatorial wind stress drives in both the positive and negative IOD phases. The easterly wind stress anomalies in the positive IOD phase (Fig. 6a) induce northward (southward) Ekman transport north (south) of the equator. More specifically, northward and southward Ekman transports mainly occur in the eastern IO which indicates the more significant wind stress anomalies in the eastern IO. The offequatorial Ekman transport induces upwelling near the equator and the weakened Ekman transport apart from the equator accompany with the downwelling there. As a result, two meridional cells that share the same upwelling near the equator form in the Ekman layer. The situation during negative IOD phases is just the opposite in the equatorial eastern IO, but the intensity is weaker than that in the positive IOD phase. In the equatorial eastern IO, the westerly wind stress anomalies initiate southward (northward) Ekman transport north (south) of the equator. The enhanced Ekman transport to the equator leads to the downwelling at the equator and the upwelling outside the equator (Fig. 6b).

Above analysis suggests that wind stress anomalies can drive the corresponding motions in the Ekman layer. Wind stress can also drive the motions in the thermocline layer. Therefore, we calculated the differences between Sverdrup transport and Ekman transport, which represents transport in the thermocline layer, to identify the indirect influence of wind stress. From a zonally averaged perspective, transport in the thermocline layer is in the opposite direction compared to the Ekman layer above it (Fig. 7). In a positive IOD phase (Fig. 7a), the off-equatorial Ekman transport must be balanced by the in-equatorial transport in the thermocline layer. This suggests that the shallow MOC will exhibit opposite anomalies in the Ekman layer relative to the thermocline layer (Fig. 7c). In a negative IOD phase (Fig. 7b, d), this situation is similar 
except for the weakened transport anomalies and shallow MOC anomalies.

\section{b. Surface ocean currents induced by the zonal wind stress}

We use the velocity at $5 \mathrm{~m}$ depth to represent the surface ocean current; Fig. 8 presents a map of the correlations of ZWI with surface ocean currents in autumn. Fig. 8 shows that there is a significant positive correlation between the ZWI and the Southwest Monsoon Current (SMC), which is caused by the southwest monsoon at $5^{\circ}$ $\mathrm{S}-5^{\circ} \mathrm{N}$ in the east-west direction, which indicates that when the westerly anomaly occurs, the SMC increases.

Fig. 9 shows surface ocean current anomalies in a positive phase year and negative phase year for the IOD. In the positive phase year for the IOD, the SMC is weakened because there is a clear westward flow anomaly between $5^{\circ} \mathrm{S}-5^{\circ} \mathrm{N}$. However, the difference is that there is a southward flow phenomenon in the southern ocean current anomaly near the equator while the northward flow is located north of the equator (Fig. 9a). In the negative phase year for the IOD, the SMC in the central to eastern basin is strengthened due to a weak eastward flow anomaly while the SMC to the west is weakened due to the weak westward flow anomaly and there is a northward flow anomaly between $5^{\circ} \mathrm{S}-0^{\circ}$. In general, surface ocean current anomalies for IOD negative phase years are less robust than those for IOD positive phase years (Fig. 9b).

\section{Summary and discussion}

This paper investigates the influence of equatorial wind stress on the equatorial Ekman transpot during IOD mature phases by analyzing the SODA dataset. The main findings are as follows. The wind stress associated with IOD mature phases can modify transport in the Ekman layer and thermocline layer which can lead to corresponding upwelling and downwelling.

In the positive phase of the IOD, cold SSTAs are present along the coasts of 
Sumatra and Java, warm SSTAs are present along the East African coast, and there is a southeast wind anomaly near the equator $\left(10^{\circ} \mathrm{S}-10^{\circ} \mathrm{N}\right)$. Therefore, the surface layer flows south in the south of the equator, sinks at $10^{\circ} \mathrm{S}$, reaches $100 \mathrm{~m}$ depth, then turns back to the north, rises at the equator, and forms a counterclockwise circulation. In contrast, the anomaly for meridional (Ekman) transport is present northward from $0^{\circ}$ to $5^{\circ} \mathrm{N}$, sinks at $5^{\circ} \mathrm{N}$, reaches $60 \mathrm{~m}$ depth, turns southward and ascends at the equator to form a clockwise circulation. As a consequence, there are two small circulation anomalies with equatorial symmetry at $100 \mathrm{~m}$ depths and the transport below 100 meters displays opposite characteristics (Fig. 11).

In contrast, in the negative phase of an IOD warm SSTAs are present in the southeast part of the Indian Ocean, cold SSTAs are present in the west, and a westerly anomaly exists near the equator. As a result, the corresponding surface transport anomaly is northward in the south of the equator, descends at the equator, reaches $60 \mathrm{~m}$ depth, turns back to the south, goes up at $5^{\circ} \mathrm{S}$, and forms a clockwise circulation. Conversely, the Ekman transport anomaly located north of the equator is southward, descends at the equator, reaches $200 \mathrm{~m}$ depth, and then returns northward and rises at $10^{\circ} \mathrm{N}$ to form an anticlockwise circulation. Thus, there are two small circulation anomalies that are symmetric about the equator at a depth of $100 \mathrm{~m}$, the equator is a sinking current, and the transport below $100 \mathrm{~m}$ is the opposite. Furthermore, the anomalies in wind stress and stream function during IOD mature periods exhibit phase asymmetry, i.e., positive phase years are greater than negative phase years.

For IOD formation, one factor is the internal variability of the Indian Ocean and the other factor is external El Niño-Southern Oscillation (ENSO) forcing (Ashok et al. 2003; Behera et al. 2006; Yang et al. 2015; Zhang et al. 2019). Hence, it is important to assess the influence of ENSO on the relationship between the EETAI and equatorial 
wind stress during IOD mature periods. For this purpose, Table 1 shows the partial correlation of the EETAI with equatorial wind stress and SON DMI after removal of the preceding DJF, MAM, JJA and SON ENSO signals for the period from 1958 to 2008. The correlation coefficient between the equatorial wind stress and EETAI is 0.82 while this decreases to 0.69 (still significant at the $99 \%$ level) after removal of the SON1 ENSO signal; i.e., it barely changes even after removing the signals of the preceding D0JF1, MAM1, JJA1 and D1JF2 ENSO signals. Except for the equatorial wind stress, the partial correlation coefficients between the SON DMI and EETAI are still significant after removal of the preceding D0JF1, MAM1, JJA1, SON1 and D1JF2 ENSO signals (Table 1). These results indicate that the equatorial wind stress is significantly correlated with the EETAI in SON, although ENSO can slightly weaken their relationship. In addition, we regress the shallow streamfunction on the ZWI both under the condition of the regular and ENSO independent indices (Fig. 10). The regression coefficient within 100 meters near the equator did not change much after removal of the SON1, D1JF2 ENSO signals, which indicates that ENSO has little effect on the relationship of equatorial wind stress and Ekman transport during the IOD mature period. This shows that ENSO may exert some influence on equatorial wind stress and Ekman transport in the year of the IOD events, but the influence is weak.

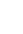

(1)

(1)




\section{Acknowledgements}

We are very grateful to NOAA for providing GHCN CAMS and (NCEP/NCAR) reanalysis data (1948-2017). This study was funded jointly by the National Natural

Global Change and Air-Sea Interaction (GASI-IPOVAI-03); the National Basis

Research Program of China (2015CB953601, 2014CB953903); and the Fundamental 
Ashok K, Guan ZY, Yamagata T (2003) A Look at the Relationship between the ENSO and the Indian Ocean Dipole. Journal of the Meteorological Society of Japan. Ser. II 81(1):41-56.

Behera SK, Luo JJ, Masson S, Rao SA, Sakuma H, Yamagata T (2006) A CGCM Study on the Interaction between IOD and ENSO. J Climate 19(9):1688-1705.

Carton JA, Chepurin G, Cao XH (2000) A Simple Ocean Data Assimilation Analysis of the Global Upper Ocean 1950-95. Part II: Results. J Phys Oceanogr 30(2):311-326.

Fischer AS, Weller RA, Rudnick DL, Eriksen CC, Lee CM, Brink KH, Fox CA, Leben

RR (2002) Mesoscale eddies, coastal upwelling, and the upper-ocean heat budget in the Arabian Sea. Deep-Sea Research II 49(12):2231-2264.

Garternicht U, Schott F (1997) Heat fluxes of the Indian Ocean from a global eddy resolving model. J Geophys Res Oceans 102(C9):21147-21159.

Huang B, Thorne PW, Banzon VF, Boyer T, Zhang HM (2017) Extended

Reconstructed Sea Surface Temperature, Version 5 (ERSSTv5): Upgrades, Validations, and Intercomparisons. J Climate 30(20):8179-8205.

Hu RJ, Liu QY, Wu S (2005) Interannual variation of the North Indian Ocean cross equatorial meridional overturning circulation. Periodical of Ocean University of China (Natural Science Edition) 35 (005): 697-702. Jiang LS, Li T (2019) Relative roles of El Niño-induced extratropical and tropical

378 forcing in generating Tropical North Atlantic (TNA) SST anomaly. Clim 
Dynam 53: 3791-3804.

Lee T (2004) Decadal weakening of the shallow overturning circulation in the South Indian Ocean. Geophys Res Lett 31(18):L18305.

Lee T, Marotzke J (1997) Inferring meridional mass and heat transports of the Indian Ocean by fitting a general circulation model to climatological data. J Geophys Res Oceans 102(C5):10585-10602.

Lee T, Marotzke J (1998) Seasonal Cycles of Meridional Overturning and Heat Transport of the Indian Ocean. J Phys Oceanogr 28(5):923-943.

Li YK, Chao JP (2013) Structure of the Indian Ocean Meridional Overturning Circulation and its relationship with the zonal wind stress. Scientia Sinica (Terrae) 43(10):1708-1716.

Li T, Wang B, Chang CP, Zhang YS (2003) A Theory for the Indian Ocean DipoleZonal Mode. J Atmos Sci 60(17):2119-2135.

Rayner NA, Parker DE, Horton EB, Folland CK, Alexander LV, Rowell DP (2003) Global analyses of sea surface temperature, sea ice, and night marine air temperature since the late nineteenth century. J Geophys Res 108(D14).

Saji NH, Goswami BN, Vinayachandran PN, Yamagata T (1999) A dipole mode in the tropical Indian Ocean. Nature 401(6751):360-363.

Schott FA, Dengler M, Schoenefeldt R (2002) The shallow overturning circulation of the Indian Ocean. Prog Oceanogr 53(1):57-103.

Sherin VR, Durand F, Gopalkrishna VV, Anuvinda S, Chaitanya AVS, BourdalléBadie R, Papa F (2018) Signature of Indian Ocean Dipole on the western boundary 
current of the Bay of Bengal. Deep Sea Research Part I: Oceanographic Research

402

403

404

405

406

407

408

409

410

411

412

413

414

415

416

Papers 136:91-106.

Stewart RH (2004) Introduction to Physical Oceanography. Prentice-Hall.

Wang WQ, Zhu XH, Wang CZ, Köhl A (2014) Deep Meridional Overturning Circulation in the Indian Ocean and Its Relation to Indian Ocean Dipole. J Climate 27(12):4508-4520.

Webster PJ, Moore AM, Loschnigg JP, Leben RR (1999) Coupled ocean-atmosphere dynamics in the Indian Ocean during 1997-98. Nature 401(6751):356-360.

Xie SP, Annamalai H, Schott FA, McCreary JP (2002) Structure and Mechanisms of South Indian Ocean Climate Variability. J Climate 15(8):864-878.

Yang Y, Xie SP, Wu LX, Kosaka Y, Lau NC, Vecchi GA (2015) Seasonality and Predictability of the Indian Ocean Dipole Mode: ENSO Forcing and Internal Variability. J Climate 28(20):8021-8036.

Zhang YZ, Li JP, Xue JQ, Feng J, Wang QY, Xu YD, Wang YH, Zheng F (2018) Impact of the South China Sea Summer Monsoon on the Indian Ocean Dipole. J Climate 31(16):6557-6573.

Zhang YZ, Li JP, Xue JQ, Zheng F, Wu RG, Ha KJ, Feng J (2019) The relative roles of the South China Sea summer monsoon and ENSO in the Indian Ocean dipole development. Clim Dynam 53(11):6665-6680.

.

(1) 


\section{Figure Captions}

FIG. 1. Positive IOD composites of wind stress anomaly (vectors; values larger than $0.01 \mathrm{~N} \cdot \mathrm{m}^{-2}$ are shown by bold arrows) and SST anomaly (shaded).

FIG. 2. Correlations of the DMI with wind stress (vector) and SST (shading) in autumn. Black stipples indicate the $99 \%$ confidence level. Only wind vectors that are significant at the $99 \%$ confidence level are plotted.

FIG. 3. (a) Correlation coefficients between the ZWI and the EETAI from MAM to DJF during 1958-2008. The dashed line indicates exceeding the 99\% confidence level. (c) Standardized time series of the ZWI (blue line), the SON DMI (red line) and the SON EETAI (yellow line). The correlation coefficient R between them is -0.81 (0.82), beyond the 99\% confidence level (Student's t test).

FIG. 4. Correlations of the ZWI with shallow streamfunction in autumn (shading). Black stipples indicate the $95 \%$ confidence level.

FIG. 5. (a) Correlations of the ZWI with Ekman transport (vector) and Ekman pumping (shading) in autumn. Black stipples indicate the 99\% confidence level. Only Ekman transport that significant at the $99 \%$ confidence level are plotted. Ekman transport is not defined near the equator $\left(2^{\circ} \mathrm{S}-2^{\circ} \mathrm{N}\right)$, where Ekman transport and Ekman pumping are not drawn. (b) Standardized time series of the ZWI (blue line), the SON DMI (red line) and the cross-equatorial Ekman transport (yellow line). The correlation coefficient $\mathrm{R}$ between them is $0.98(-0.77)$, beyond the $99 \%$ confidence level (Student's t test). 
FIG. 6. The Ekman transport (vectors; Sv) and Ekman pumping (shading) anomaly (a) of positive IOD composites and (b) of negative IOD composites. (c) The composite difference of the Ekman transport (vectors; Sv) and Ekman pumping (shading) of positive IOD and negative IOD. Black stipples indicate the $95 \%$ confidence level. Only vectors that are significant at the $95 \%$ confidence level are plotted.

FIG. 7. (a) The meridional seawater transport and (c) the shallow streamfunction anomaly of positive IOD composites. (b) The meridional seawater transport and (d) the shallow streamfunction anomaly of negative IOD composites. The composite difference of (e) the meridional seawater transport and (f) the shallow streamfunction of positive IOD and negative IOD. Solid stipples indicate the $90 \%$ confidence level. In (a), (b) and (e), the blue lines indicate Ekman transport, the orange lines stand for Sverdrup transport, and the red lines indicate the difference between Sverdrup transport and Ekman transport. In all subgraphs, the transverse axis represents latitude.

FIG. 8. Correlation of the ZWI with the surface ocean current (vector) in autumn. Only current vectors that are significant at the 95\% confidence level are plotted.

FIG. 9. The surface ocean current anomaly (vectors; $\mathrm{m} / \mathrm{sec}$ ) of (a) positive IOD composites and (b) negative IOD composites. (c) The composite difference of the surface ocean current (vectors; $\mathrm{m} / \mathrm{sec}$ ) of positive IOD and negative IOD. Only current vectors that are significant at the $95 \%$ confidence level are plotted.

FIG. 10. (a) Regression of the shallow streamfunction on the ZWI. (b) Partial regression of the shallow streamfunction on the ZWI after removal of SON1 ENSO 
signals. (c) Partial regression of the shallow streamfunction on the ZWI after removal of D1JF2 ENSO signals(D1JF2, where 1 and 2 refers to the concurrent and next year, respectively).Black stipples in (a) - (c) indicate the $95 \%$ confidence level.

FIG. 11. Schematic diagram of the equatorial wind stress affecting the equatorial Ekman transport in the positive phase of IOD. The blue shadow indicates the significant negative SSTAs, and red shadow indicates the positive SSTAs. The small black arrows represent the wind stress of the sea surface, the thick blue arrows represent Ekman transport, and the thin blue arrows represent the shallow MOC of the zonal integration. 
TABLE 1. The partial correlation coefficients of the SON SMOCAI with the ZWI and 488 the SON DMI during 1958 - 2008. The season in brackets denotes the averaged season 489 of the different index, i.e., Rm-Niño3.4 (Pre-D0JF1/D1JF2) indicates the removal of 490 the preceding/next boreal winter ENSO signals (D0JF1, D1JF2, where 0 refers to 491 previous year, 1 refers to concurrent year and 2 refers to next year). 

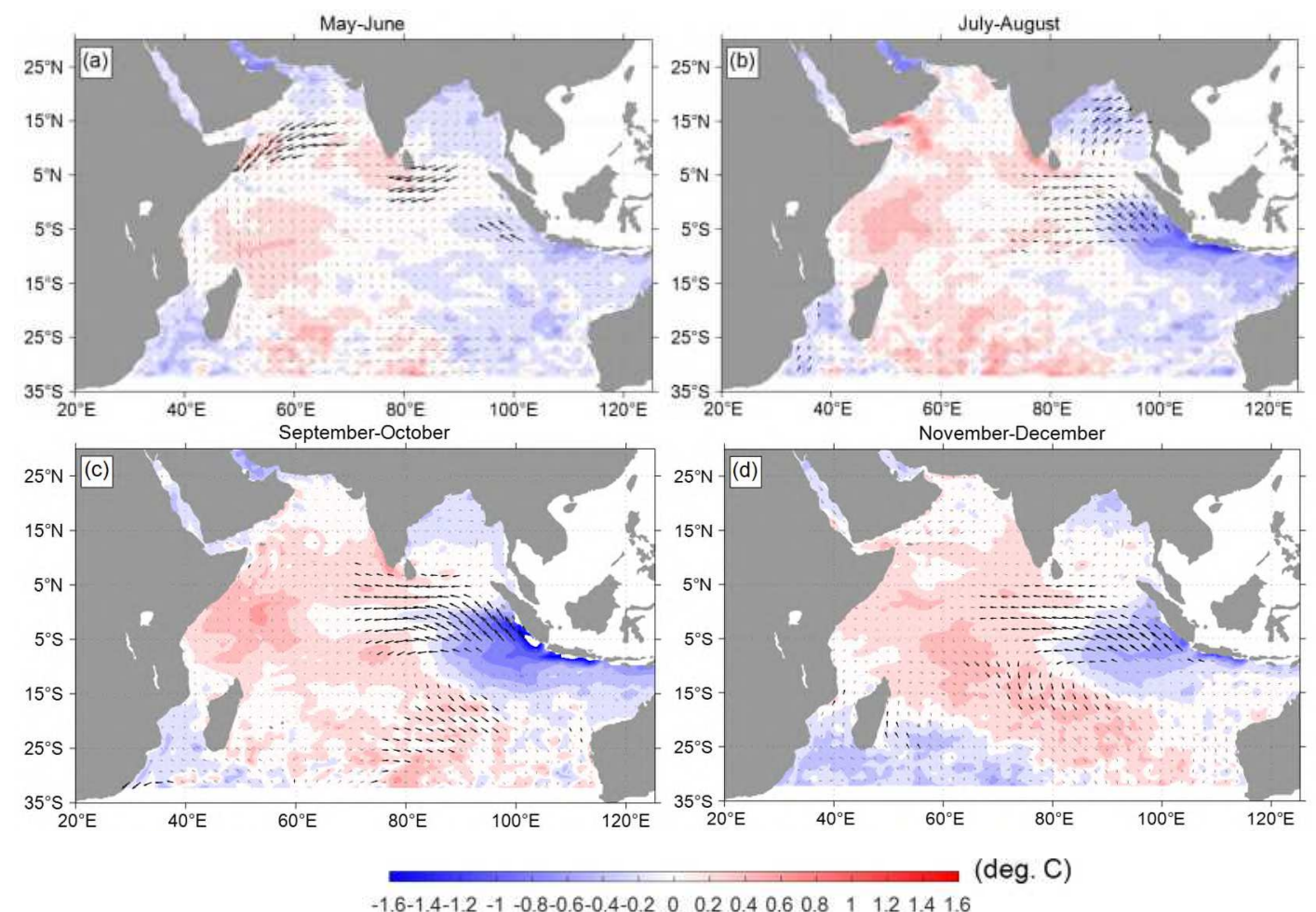

500

-1.6-1.4-1.2 - $-1-0.8-0.6-0.4-0.2 \quad 0 \quad 0.20 .40 .60 .8 \quad 1 \quad 1.21 .41 .6$

FIG. 1. Positive IOD composites of wind stress anomaly (vectors; values larger than 


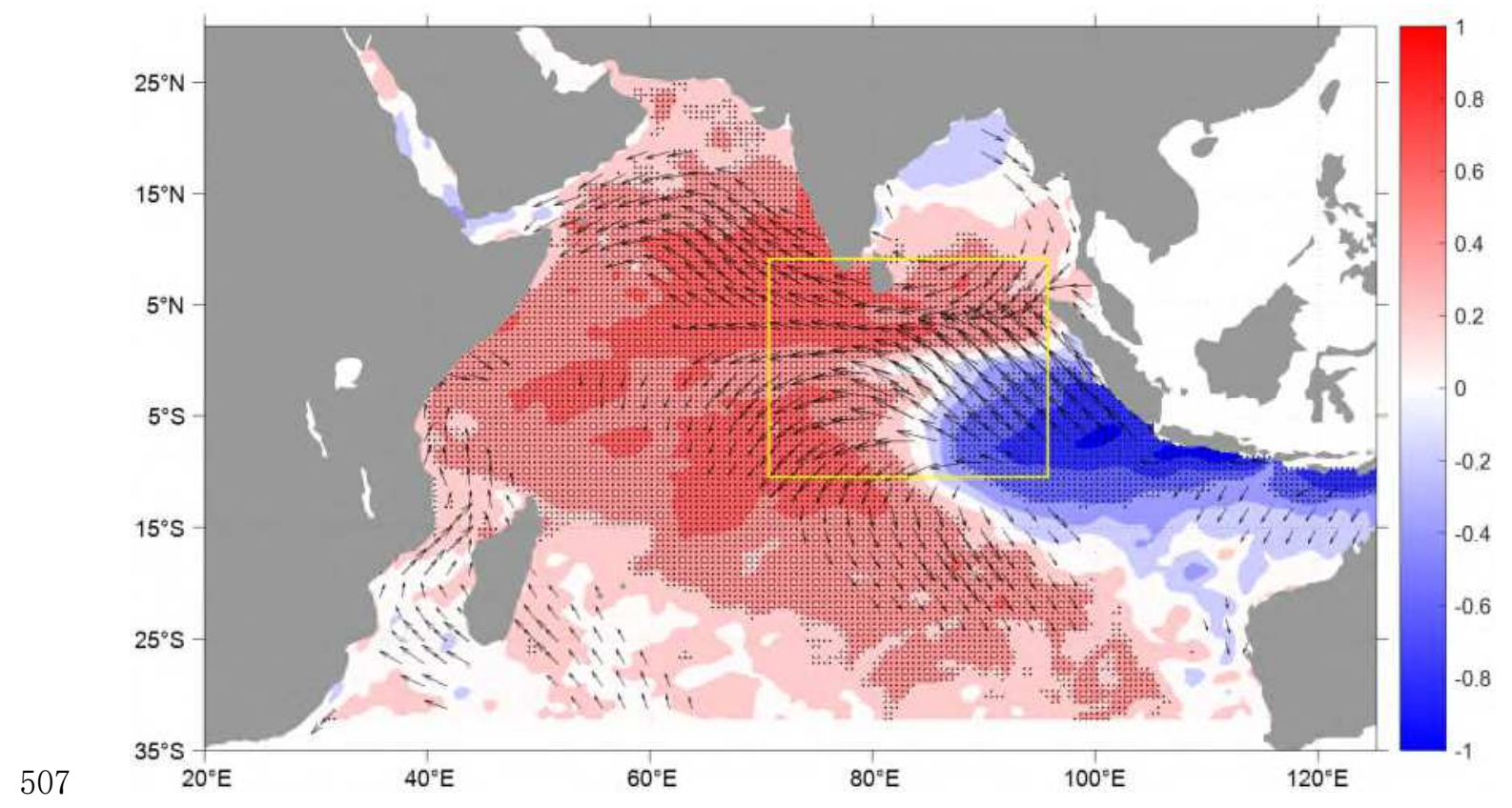

508 FIG. 2. Correlations of the DMI with wind stress (vector) and SST (shading) in autumn.

Black stipples indicate the $99 \%$ confidence level. Only wind vectors that are significant

510 at the $99 \%$ confidence level are plotted. 

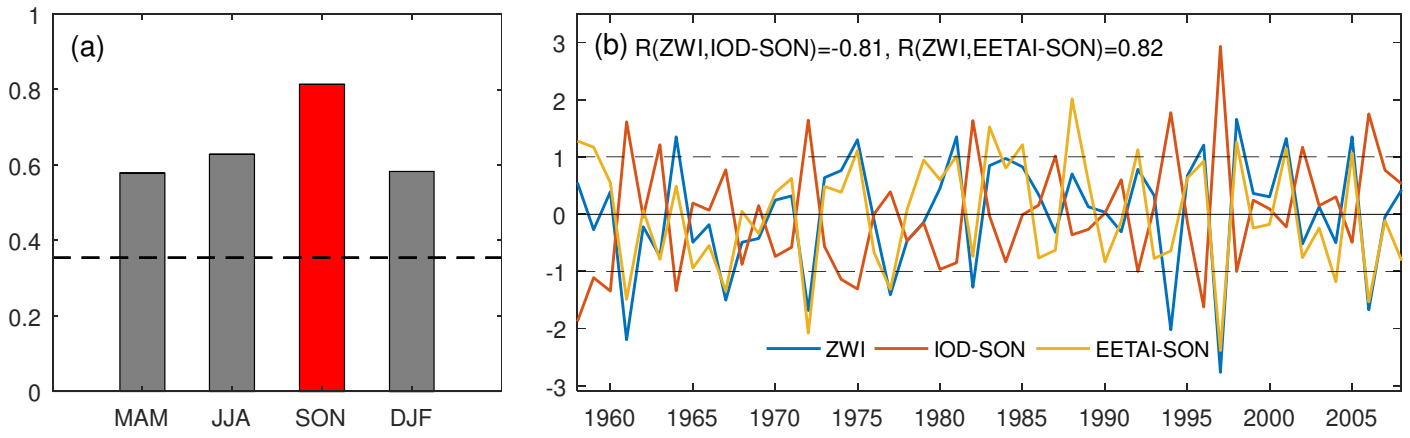

FIG. 3 (a) Correlation coefficients between the ZWI and the EETAI from MAM to DJF beyond the $99 \%$ confidence level (Student's t test). 


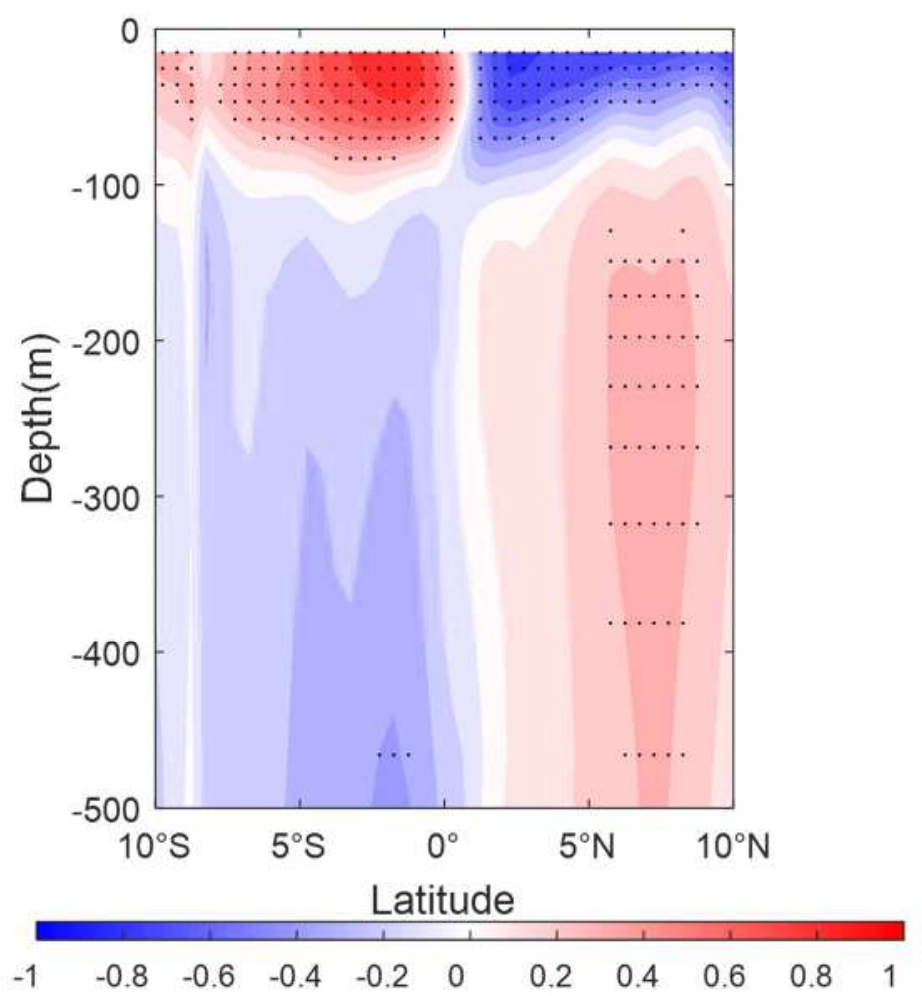

533 FIG. 4. Correlations of the ZWI with shallow streamfunction in autumn (shading).

534 Black stipples indicate the $95 \%$ confidence level. 

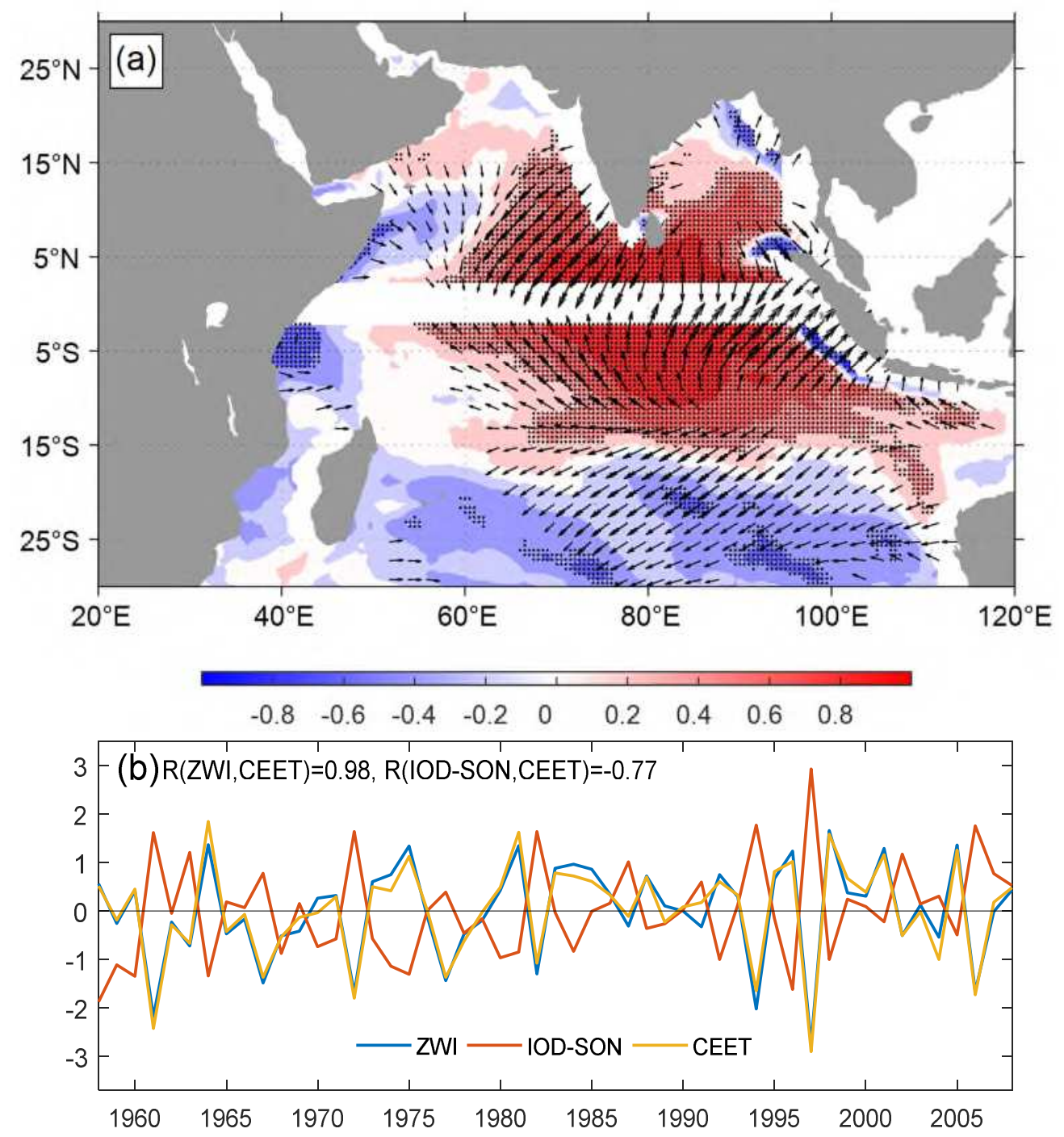

FIG. 5. (a) Correlations of the ZWI with Ekman transport (vector) and Ekman

543 pumping (shading) in autumn. Black stipples indicate the 99\% confidence level. Only

544 Ekman transport that significant at the $99 \%$ confidence level are plotted. Ekman

545 transport is not defined near the equator $\left(2^{\circ} \mathrm{S}-2^{\circ} \mathrm{N}\right)$, where Ekman transport and Ekman pumping are not drawn. (b) Standardized time series of the ZWI (blue line), the SON DMI (red line) and the cross-equatorial Ekman transport (yellow line). The correlation coefficient $\mathrm{R}$ between them is 0.98 (-0.77), beyond the $99 \%$ confidence level (Student's $t$ test). 

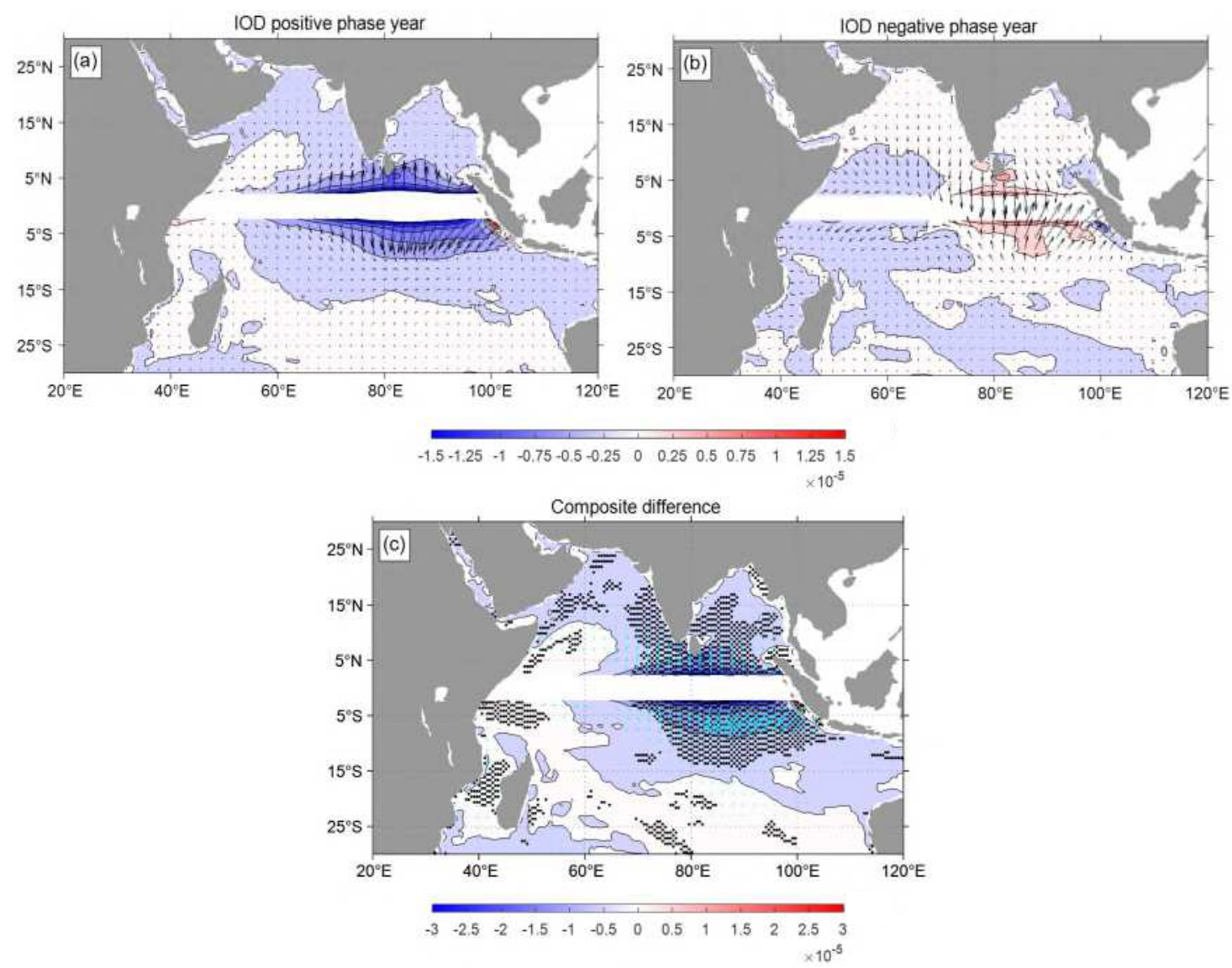

FIG. 6. The Ekman transport (vectors; Sv) and Ekman pumping (shading) anomaly (a)

552 of positive IOD composites and (b) of negative IOD composites. (c) The composite

553 difference of the Ekman transport (vectors; Sv) and Ekman pumping (shading) of

554 positive IOD and negative IOD. Black stipples indicate the $95 \%$ confidence level. Only

555 vectors that are significant at the $95 \%$ confidence level are plotted. 

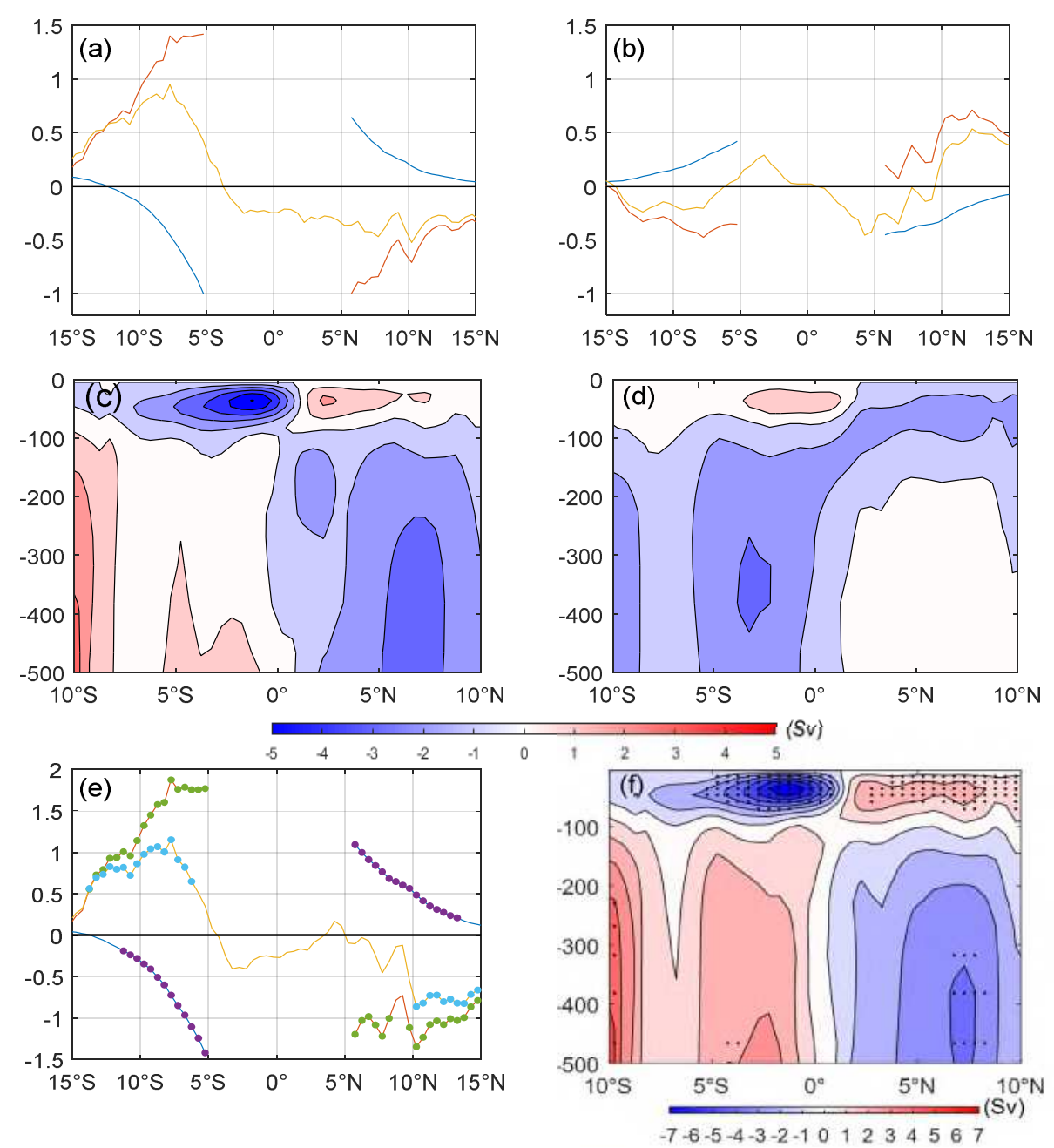

FIG. 7. (a) The meridional seawater transport and (c) the shallow streamfunction anomaly of positive IOD composites. (b) The meridional seawater transport and (d) the shallow streamfunction anomaly of negative IOD composites. The composite difference of (e) the meridional seawater transport and (f) the shallow streamfunction of positive IOD and negative IOD. Solid stipples indicate the $90 \%$ confidence level. In (a), (b) and (e), the blue lines indicate Ekman transport, the orange lines stand for Sverdrup transport, and the red lines indicate the difference between Sverdrup transport and Ekman transport. In all subgraphs, the transverse axis represents latitude. 


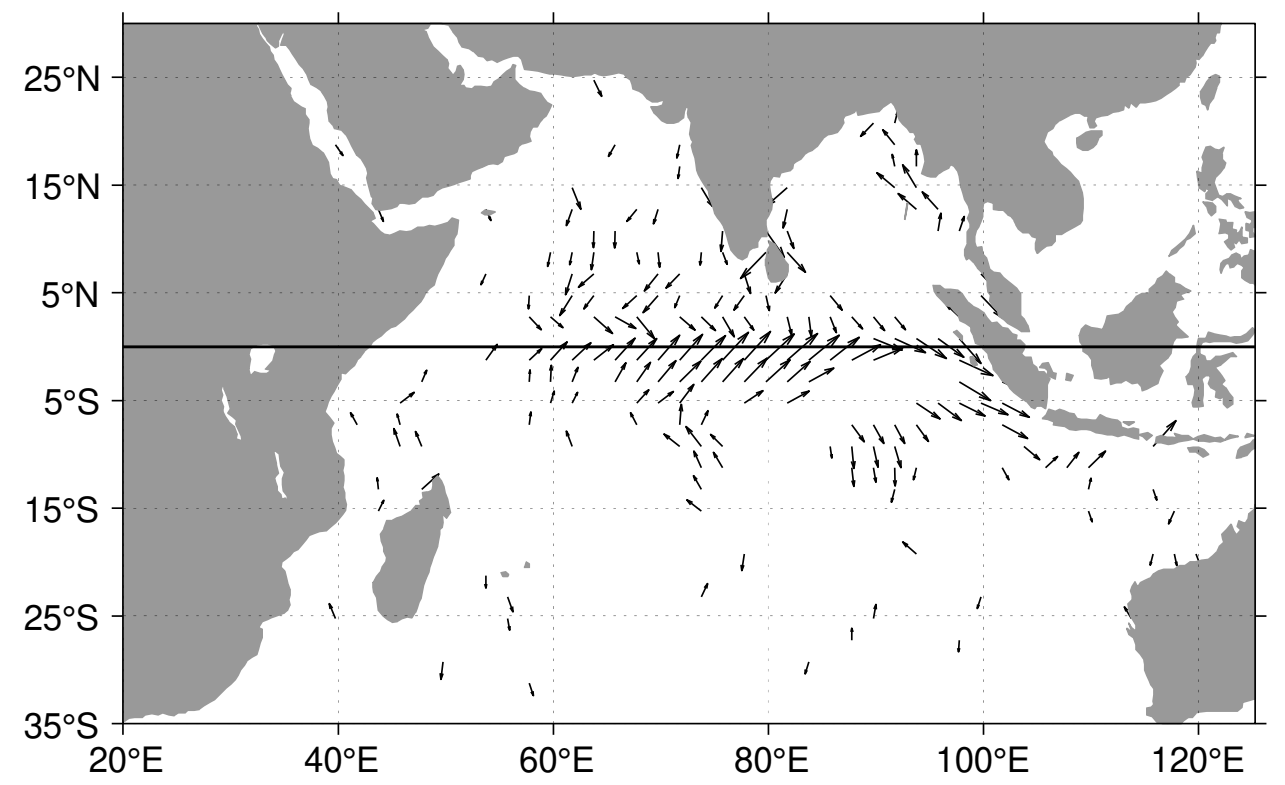

566

567 FIG. 8. Correlation of the ZWI with the surface ocean current (vector) in autumn.

568 Only current vectors that are significant at the 95\% confidence level are plotted. 

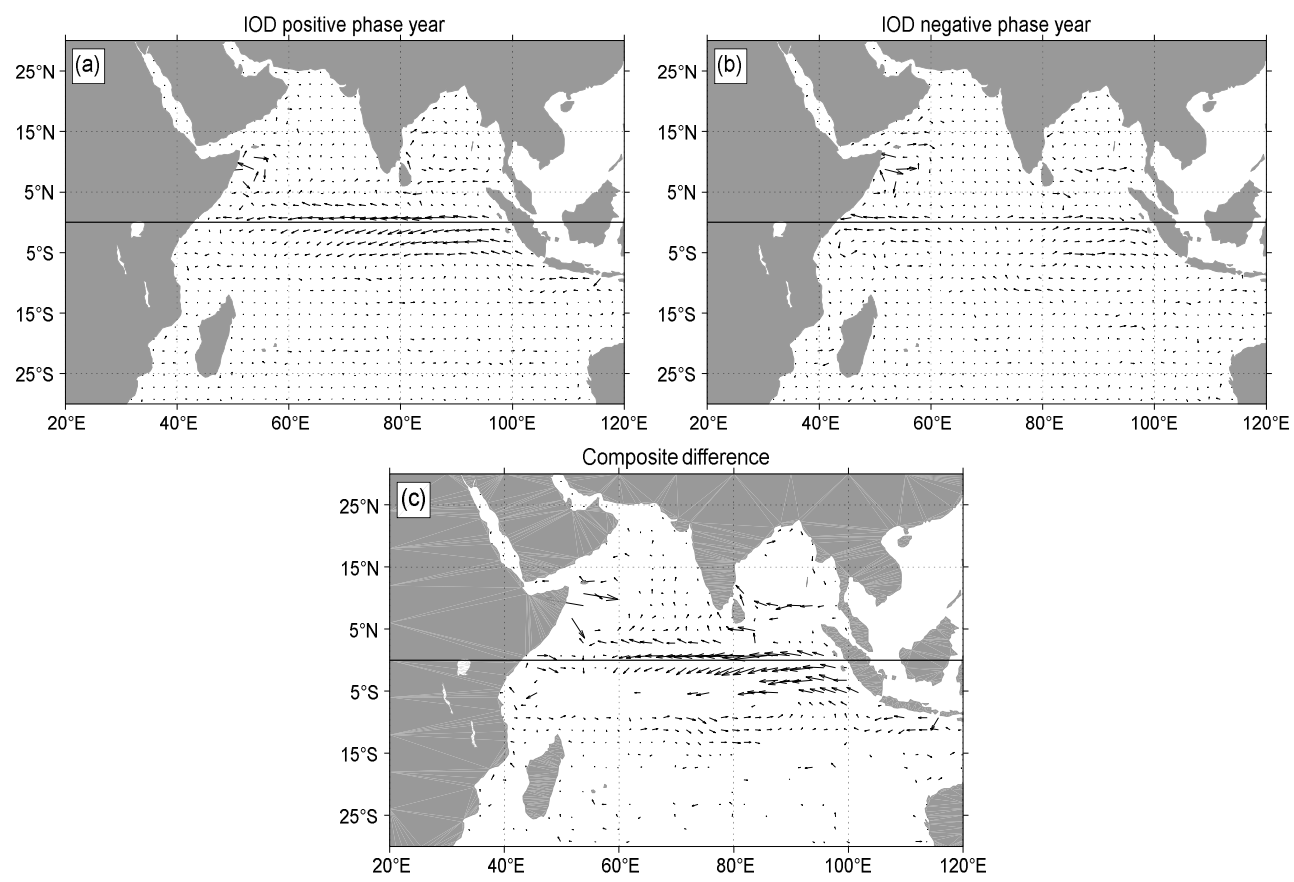

570 FIG. 9. The surface ocean current anomaly (vectors; $\mathrm{m} / \mathrm{sec}$ ) of (a) positive IOD

571 composites and (b) negative IOD composites. (c) The composite difference of the 572 surface ocean current (vectors; $\mathrm{m} / \mathrm{sec}$ ) of positive IOD and negative IOD. Only current 573 vectors that are significant at the $95 \%$ confidence level are plotted. 

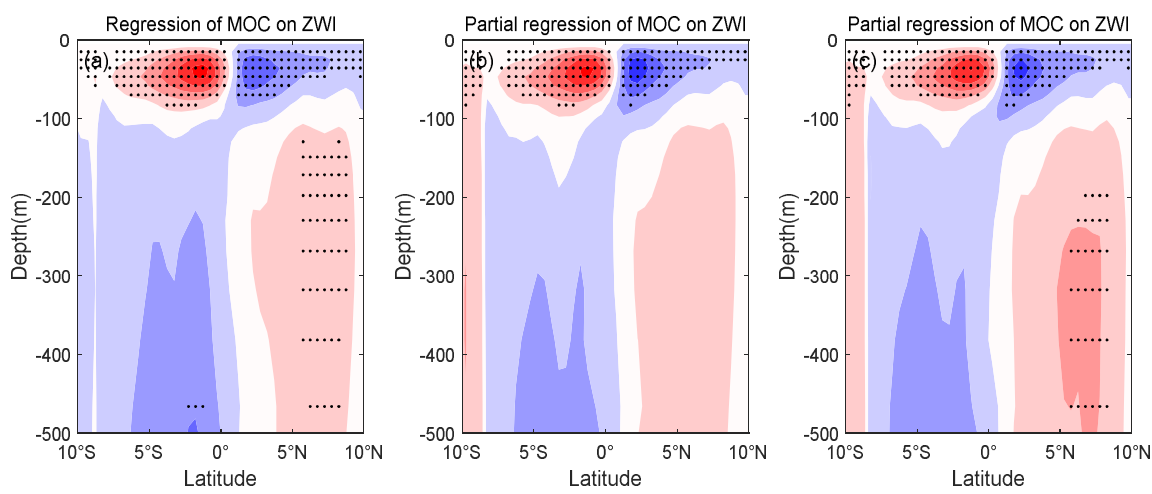

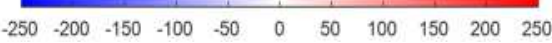

FIG. 10. (a) Regression of the shallow streamfunction on the ZWI. (b) Partial regression of the shallow streamfunction on the ZWI after removal of SON1 ENSO signals. (c) Partial regression of the shallow streamfunction on the ZWI after removal of D1JF2 ENSO signals(D1JF2, where 1 and 2 refers to the concurrent and next year, respectively).Black stipples in (a) - (c) indicate the $95 \%$ confidence level. 


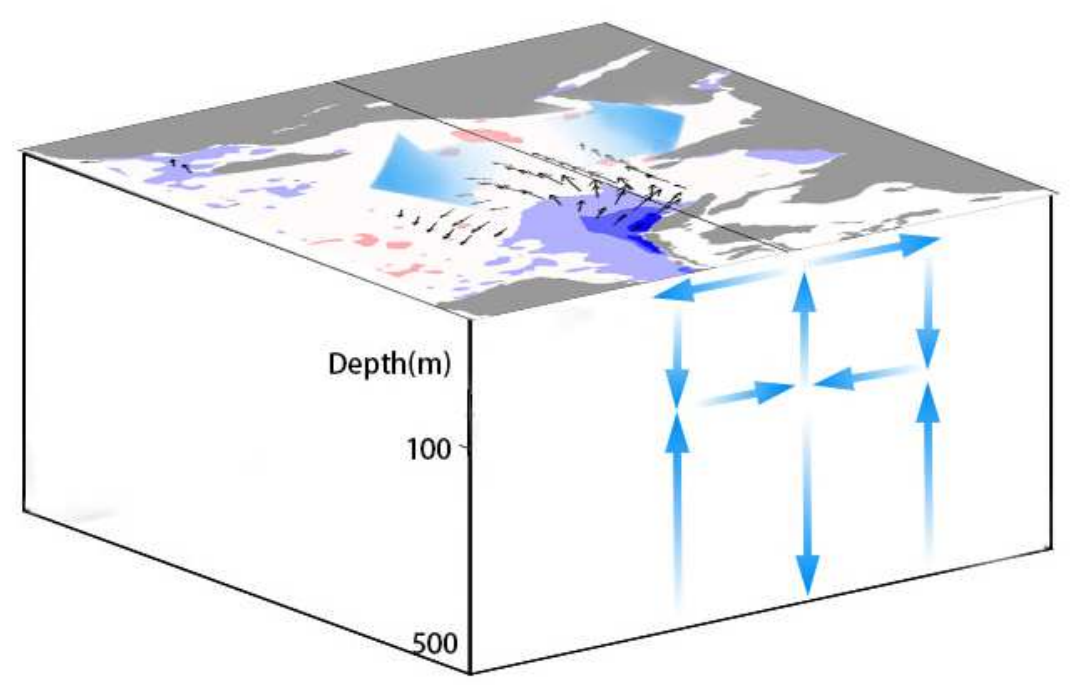

590 FIG. 11. Schematic diagram of the equatorial wind stress affecting the equatorial 591 Ekman transport in the positive phase of IOD. The blue shadow indicates the significant negative SSTAs, and red shadow indicates the positive SSTAs. The small black arrows represent the wind stress of the sea surface, the thick blue arrows represent Ekman transport, and the thin blue arrows represent the shallow MOC of the zonal integration. 
TABLE 1. The partial correlation coefficients of the SON EETAI with the ZWI and the

604 SON DMI during 1958 - 2008. The season in brackets denotes the averaged season of 605 the different index, i.e., Rm-Niño3.4 (Pre-D0JF1/D1JF2) indicates the removal of the 606 preceding/next boreal winter ENSO signals (D0JF1, D1JF2, where 0 refers to previous 607 year, 1 refers to concurrent year and 2 refers to next year).

\begin{tabular}{lcccccc}
\hline & \multicolumn{5}{c}{ Partial correlation } \\
\cline { 3 - 7 } & correlation & $\begin{array}{c}\text { Rm-Nino-3.4 } \\
\text { (Pre-D0JF1) }\end{array}$ & $\begin{array}{c}\text { Rm-Nino-3.4 } \\
\text { (Pre-MAM1) }\end{array}$ & $\begin{array}{c}\text { Rm-Nino-3.4 } \\
\text { (Pre-JJA1) }\end{array}$ & $\begin{array}{c}\text { Rm-Nino-3.4 } \\
\text { (SON1) }\end{array}$ & $\begin{array}{c}\text { Rm-Nino-3.4 } \\
\text { (Pre-D1JF2) }\end{array}$ \\
\hline (ZWI, SON-EETAI) & 0.82 & 0.81 & 0.82 & 0.72 & 0.69 & 0.72 \\
\hline (SON-DMI, SON-EETAI) & -0.79 & -0.78 & -0.79 & -0.67 & -0.64 & -0.70 \\
\hline
\end{tabular}

